\title{
Shear-wave splitting analysis of the upper mantle at the Niigata-Kobe Tectonic Zone with the data of the Joint Seismic Observations at NKTZ
}

\author{
Takashi Iidaka $^{1}$, Yoshihiro Hiramatsu ${ }^{2}$, and The Japanese University Group of the Joint Seismic Observations at NKTZ \\ ${ }^{1}$ Earthquake Research Institute, University of Tokyo, Yayoi 1-1-1, Bunkyo, Tokyo, Japan \\ ${ }^{2}$ Graduate School of Natural Science and Technology, Kanazawa University, Kanazawa, Japan
}

(Received December 26, 2007; Revised August 11, 2008; Accepted September 9, 2008; Online published February 18, 2009)

\begin{abstract}
We conducted seismic observations with a spatially high density seismic network at the Niigata-Kobe Tectonic Zone, central Japan. The seismic network was used for the analysis of shear-wave splitting. Large lateral variations were found in the polarization direction data: the northern part of the research area yields polarization directions of NW-SE (Region A), the central part of the research area with the polarization direction of NNE-SSW (Region B), the eastern part of the research area with the polarization direction of NE-SW (Region C), and the southern part of the research area with the polarization direction of E-W (Region D). The polarization directions in Regions B and C could be explained by the preferred orientation of olivine caused by the flow of the subducting Philippine Sea plate. However, the cause of anisotropic region which was related to the heterogeneous structure was also plausible. The polarization direction in Region A might be related to the flow caused by both of the subducting Philippine Sea and Pacific slabs. The polarization direction at the Region D could not be produced by the flow in the wedge and might be related to an anisotropic region beneath the slab. The lateral variation of the polarization direction does not support a model that the NKTZ is a collision region.
\end{abstract}

Key words: Shear-wave splitting, NKTZ, anisotropy, Atotsugawa fault, $S$ wave.

\section{Introduction}

Recently, a spatially high dense GPS array (GEONET by Geographical Survey Institute in Japan) indicated the existence of a high strain rate zone along the Japan Sea coast, which was named as the Niigata-Kobe Tectonic Zone (NKTZ) (e.g., Sagiya et al., 2000). Many historical large earthquakes have occurred inside the NKTZ. The large, right lateral Atotsugawa fault is located in the NKTZ. A historical large earthquake, Hietsu earthquake, is considered to be caused by the Atotsugawa fault. Understanding of the cause of the NKTZ will be important to know the concentration and accumulation mechanisms of stress and strain on the active faults in Japan. The area is one of the best locations to study the relation between the mechanism of inland earthquakes and the high strain rate zone.

The cause of the NKTZ has been researched by many scientists. Several models have been proposed for the mechanism of the NKTZ (e.g., Shimazaki and Zhao, 2000; Iio et al., 2002; Hyodo and Hirahara, 2003; Yamasaki and Seno, 2005). The observed horizontal displacement rates in the NKTZ were investigated, quantitatively, by three kinematic models which were named as the detachment model (Hirahara et al., 1989); the collision model (Shimazaki and Zhao, 2000; Heki and Miyazaki, 2001; Miyazaki and Heki, 2001); and the back-slip model (Mazzotti et al., 2000). Different mechanisms are considered for the cause of the NKTZ. The source area of the cause of the NKTZ differs in each

Copyright (c) The Society of Geomagnetism and Earth, Planetary and Space Sciences (SGEPSS); The Seismological Society of Japan; The Volcanological Society of Japan; The Geodetic Society of Japan; The Japanese Society for Planetary Sciences; TERRAPUB model. Three areas, which are upper-crust, lower-crust, and uppermost-mantle, are considered as the candidates for the cause of the NKTZ. It is very important to know the seismic structure at the crust and upper mantle to reveal the cause of the NKTZ. The Japanese University Group of the Joint Seismic Observations at NKTZ has been conducting seismic observations at the NKTZ for the five years period starting from 2004 (The Japanese University Group of the Joint Seismic Observations at NKTZ, 2005).

It is well known that elastic anisotropy of the earth is closely related to mantle dynamics. The cause of the anisotropic zones has been researched by many scientists. Two possible models have been proposed for the explanation of the observed shear-wave splitting: one is the olivine alignment model (Hess, 1964; Sugimura and Uyeda, 1967; Francis, 1969; Fuchs, 1977), the other is the crack alignment model (Nur and Simmons, 1969; Gupta, 1973; Crampin, 1978; Crampin et al., 1980). Seismic anisotropy beneath the ocean is commonly observed and is probably related to seafloor spreading (e.g., Bibee and Shor, 1976; Fuchs, 1977). Refraction surveys showed that the directions of the maximum $P n$ velocities were parallel or nearly parallel to the spreading directions. Such seismic anisotropy had been anticipated by the observation of Birch (1960, 1961) that compressional wave velocities vary with propagation direction in mantle rocks due to the preferred orientation of olivine crystals.

If the anisotropy found in the mantle wedge beneath Japan results from preferred olivine orientation, the observed seismic data provides information on the mineral fabric in the upper mantle, which may lead to a better under- 
standing of flow mechanism and flow directions beneath island arcs. Large-scale flow is inferred for the mantle wedge. Quantitative models of subduction zones have been investigated using theoretical calculations (e.g., McKenzie, 1979; Hsui and Toksoz, 1979). The formation and spreading of marginal basins are due to convective flow in the mantle induced by the subducting slab. The flow lines below an island arc are parallel to the earth's surface. The anisotropy of peridotite samples originating in the upper mantle has also been investigated (Peselnick et al., 1974; Peselnick and Nicolas, 1978; Nicolas and Christensen, 1987; Audoine et al., 2004). In the Kuril-Kamchatka subduction zone, seismic anisotropy was studied by Fischer and Yang (1994). The cause of the anisotropy was interpreted as the preferred orientations of olivine because of the good correlation between the observed anisotropy and the trend of preferred orientations of olivine expected from the strain pattern of the plate convergence.

The crack alignment model is also one of the candidates for the cause of the anisotropy (e.g., Crampin, 1981). A concentration of aligned cracks has its effective elastic constants arranged in some form of anisotropic symmetry. Crustal anisotropy has been researched by many scientists (e.g., Kaneshima, 1990). The cause of crustal anisotropy was interpreted as the alignment of cracks because the polarization direction was consistent with the direction of maximum shear-stress. On the other hand, it is hard to expect that open cracks exist in the mantle wedge because the confining pressure is considered to be high. The cause of mantle anisotropy was, therefore, considered usually as the preferred orientation of olivine crystals (e.g., Silver and Chan, 1991; Nakajima and Hasegawa, 2004).

However, the melt filled crack model has been proposed for the cause of the anisotropic zone in the mantle wedge (e.g., Ando et al., 1986; Ando, 1986; Iidaka and Obara, 1994, 1995; Hiramatsu et al., 1998). In the mantle wedge, the existence of rising magma is expected from petrological studies (e.g., Tatsumi et al., 1983). The heterogeneous structure caused by rising magma leads to elastic constants arranged in some form of anisotropic symmetry, resulting in anisotropic region. A magma formation model was suggested by many scientists (e.g., Tatsumi et al., 1983): the slab-derived fluid phases react with mantle wedge material to produce hydrated peridotites, which are dragged downward on the slab towards regions of high pressure and temperature. $\mathrm{H}_{2} \mathrm{O}$ released from the hydrated peridotite layer causes partial melting of mantle wedge peridotite to produce initial magmas in the subduction zone. A number of diapirs can be produced beneath the volcanic front which may be governed by the higher rate of supply of $\mathrm{H}_{2} \mathrm{O}$ from the hydrated peridotite layer in those regions. Mantle diapirs start rising from a partially molten zone. It is expected that alignments of melt-filled cracks produce anisotropic zones. Iidaka and Obara (1995) observed the large and small shear-wave splitting values in the back-arc and in the fore-arc sides of the volcanic front, respectively. The depth of the anisotropic zone was estimated to be $50 \mathrm{~km}-150 \mathrm{~km}$. An extremely low- $Q$ area obtained by tomographic study (Sekiguchi, 1991) corresponded to the anisotropic region. The large shear-wave splitting at the back-arc side of the

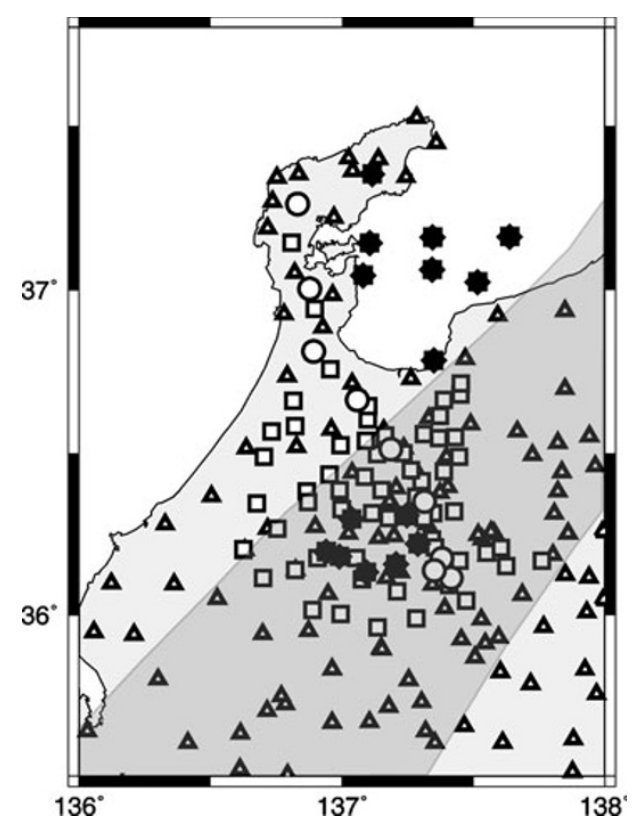

Fig. 1. Location map of seismic stations and earthquakes. The stars denote epicenters of deep earthquakes. The seismic stations are shown by open symbols. The open triangles are permanent seismic stations of Hi-net and universities. The open squares are temporary seismic stations operated during this study. The nine broad-band seismic stations are shown by open circles. The slightly shaded area denotes the NKTZ.

volcanic front was considered to be caused by the rising magma in the mantle wedge.

The elastic anisotropy of the earth is closely related to mantle dynamics. Studies of shear-wave splitting are important to study the mantle dynamics beneath the NKTZ. The spatial distribution of the observed shear-wave splitting is important information to learn the dynamics of the research area. In the Chubu region, central Japan, seismic anisotropy and velocity structure had been researched (e.g., Ando et al., 1983; Hirahara et al., 1989; Hiramatsu et al., 1998). The results suggested that a large anisotropic region existed in the mantle wedge. An east-west fast polarization direction $\left(\mathrm{N} 95^{\circ} \mathrm{E}\right)$ was obtained at the southern part of the Chubu region. At the northern part of the research area, the polarization direction of $\mathrm{N} 20^{\circ} \mathrm{E}$ was obtained. The observed maximum value of the differential time of the split shear-waves was around $1 \mathrm{sec}$. This large differential time was considered to be caused by the mantle region. Hiramatsu et al. (1998) tried to estimate a spatial variation of the anisotropic zone. The anisotropic zone was estimated at depth of about $100 \mathrm{~km}-170 \mathrm{~km}$ from a grid search of both the size and the location of the optimum zone that gave the minimum residual between the theoretical splitting parameters and the observed ones. In the previous studies, the sparse distribution of the seismic stations, however, prevents high resolution mapping of the lateral heterogeneity of the anisotropic regions. In this study, we provide a shear wave splitting map with spatially high resolution using high dense seismic networks.

However, lack of the spatial distribution of the seismic stations prevents understanding of the mantle dynamics beneath the NKTZ. We conducted temporary seismic observation with 73 seismic stations at the NKTZ area (The 
Table 1. List of earthquakes

\begin{tabular}{ccccc}
\hline Origin time & Lat. $\left({ }^{\circ}\right)$ & Long. $\left({ }^{\circ}\right)$ & Dep. $(\mathrm{km})$ & $M$ \\
\hline 20050403071724.76 & 36.196 & 136.940 & 284.9 & 3.2 \\
20050531014252.39 & 37.163 & 137.638 & 253.7 & 2.7 \\
20050703061329.47 & 37.025 & 137.516 & 257.0 & 2.6 \\
20050729124940.25 & 36.133 & 137.093 & 276.2 & 3.1 \\
20050813195613.97 & 37.045 & 137.081 & 265.0 & 2.9 \\
2005090404513.55 & 36.181 & 136.990 & 273.3 & 3.5 \\
20050912083421.01 & 37.354 & 137.114 & 280.0 & 2.5 \\
20051122020254.86 & 36.785 & 137.349 & 261.0 & 2.9 \\
2005122705146.90 & 36.158 & 137.205 & 268.3 & 3.9 \\
20060611023330.29 & 37.144 & 137.105 & 266.4 & 3.6 \\
2006080206257.98 & 36.221 & 137.289 & 272.1 & 3.2 \\
20060816110718.41 & 37.162 & 137.345 & 264.5 & 2.8 \\
20060903170845.36 & 36.308 & 137.247 & 271.6 & 4.2 \\
20061026220056.90 & 37.063 & 137.343 & 251.3 & 3.1 \\
2006121918454.14 & 36.297 & 137.037 & 276.0 & 3.9 \\
\hline
\end{tabular}

Japanese University Group of the Joint Seismic Observations at NKTZ, 2005). The shear-wave splitting of the area is researched by the use of the seismic network.

\section{Data}

The seismic data of the Japanese university joint seismic observations and Hi-net data operated by the National Research Institute for Earth Science and Disaster Prevention are used (Fig. 1) (The Japanese University Group of the Joint Seismic Observations at NKTZ, 2005). Most of the seismic stations have three-component seismograms with natural frequency of $1 \mathrm{~Hz}$. At nine seismic stations, a broadband three-component seismometer with the frequency band of $0.03-50 \mathrm{~Hz}$ was installed.

We used earthquakes which were deeper than $250 \mathrm{~km}$ (Fig. 1, Table 1). The earthquakes occurred from Jan. 1, 2005 to Dec. 31, 2006 are used. Seismic rays with incident angles smaller than 30 deg were used to avoid distortions in waveform because the use of such waves would lead to a false shear-wave anisotropy because of the phase shift between SH and SV components (e.g., Nuttli, 1961; Mendiguren, 1969).

\section{Method}

Shear-wave splitting is usually expressed by two parameters, the fast polarization azimuth $\phi$ (in degrees), and the time-lag $\tau$ (in seconds), which is the delay time between the fast and slow components of a shear wave. We use the following techniques to determine the shear-wave splitting (Fukao, 1984). A band-pass filter with a frequency window of $0.2 \mathrm{~Hz}-5 \mathrm{~Hz}$ is used for waveforms. We pick $S$ waves from individual seismograms. We calculated the crosscorrelation of the two horizontal seismogram components over a grid $-90^{\circ}$ to $+90^{\circ}$ for $\phi$ and a window of $4 \sec$ for $\tau$ with increments of $1^{\circ}$ and $0.01 \mathrm{~s}$, respectively. The time-lag $\tau$ (in seconds) and the fast polarization azimuth $\phi$ (in degree) are defined to be the values that yielded the maximum correlation (Fig. 2). In order to confirm the resulted splitting parameters, $\phi$ and $\tau$, we calculate anisotropy-corrected seismograms. As shown in Fig. 2, the anisotropy-corrected particle motion shows a linear orbit, as expected from the source mechanism of the earthquake. Bad waveform data which were contaminated by large noise are rejected for the analysis. The obtained linear polarization suggests that the waveform splitting is caused by the anisotropic medium, not by seismic noise.

\section{Results and Discussion}

The observed shear-wave splitting shows a clear regional variation on the polarization directions in this study (Fig. 3). The research area was divided into four regions based on the observed polarization direction (Fig. 4). One is the northern part of the observed area (Region A). In this area, the average polarization direction of NW-SE is obtained. In the central part of the research area (Region B), the polarization directions of NNE-SSW are obtained. The eastern part of this research area indicates NE-SW polarization directions (Region C). E-W polarization data is obtained at the seismic stations located in the southern part of the research area (Region D). The observed value of the shearwave splitting is the accumulated value of anisotropy along the ray path. The value contains the shear-wave splitting values of crust and mantle wedge. We conclude that the anisotropic zone has to be located in the mantle wedge based on the following reasons. The shear-wave splitting values at the crust had been researched by previous studies (e.g., Kaneshima, 1990). Localized anisotropic zones of the crust have been well investigated in Japan, and the maximum time-lag value caused by the crust was found to be less than $0.2 \mathrm{sec}$. The observed average time-lag values are much larger than the crustal maximum time lag value of $0.2 \mathrm{sec}$ (Fig. 3). The direction of maximum horizontal compression in Japan was research by Ando (1979). The maximum horizontal compression direction is shown in Fig. 3. Mizuno et al. (2005) studied crustal anisotropy around the Atotsugawa fault, which is an active fault located in the central part of our research area. The polarization direction cause by the crustal anisotropy is consistent with the direc- 
(A)

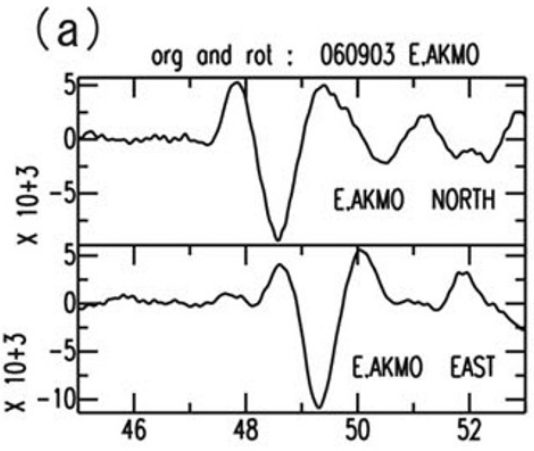

(b)

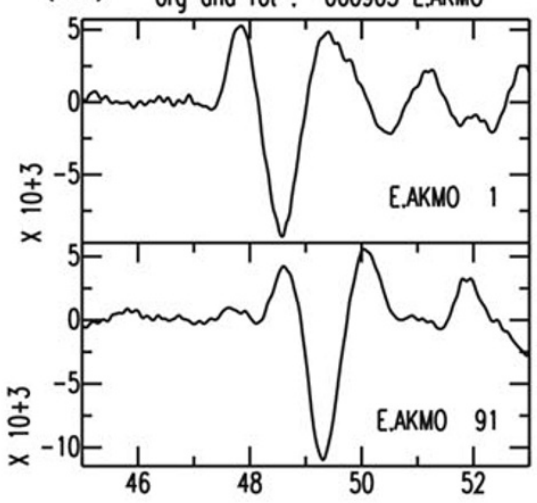

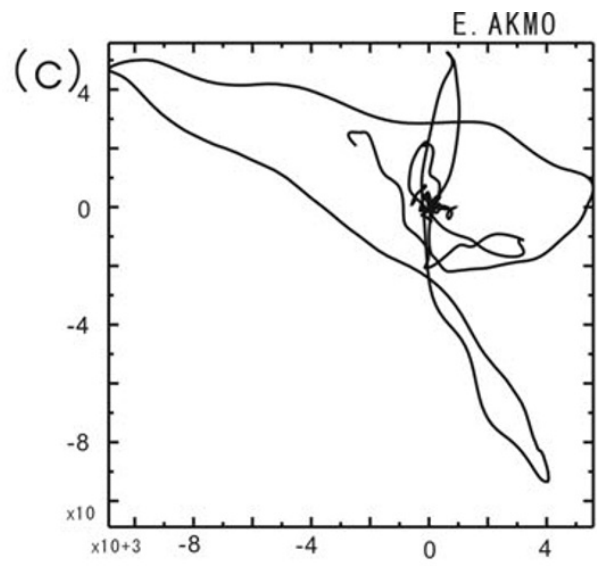

(d)

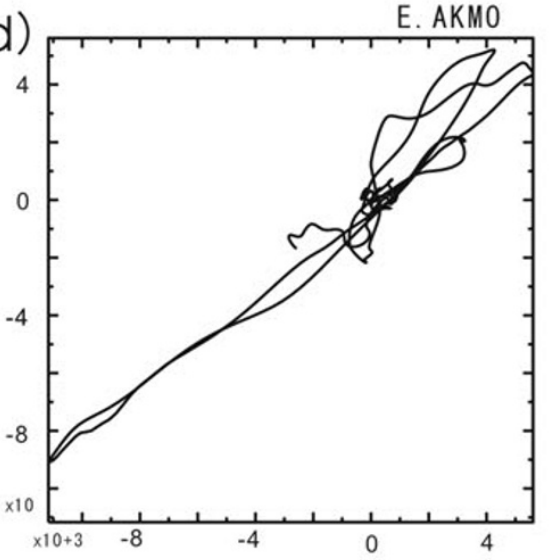

(B)

(a)

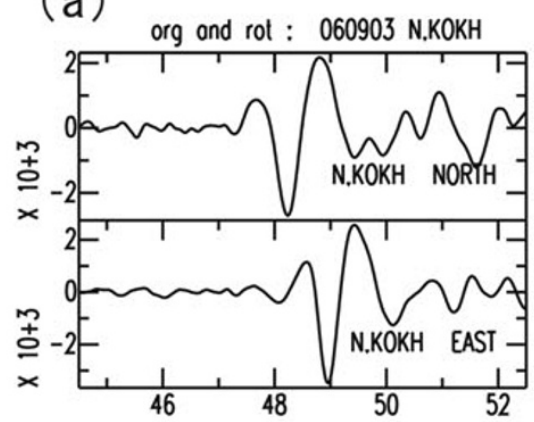

(b)

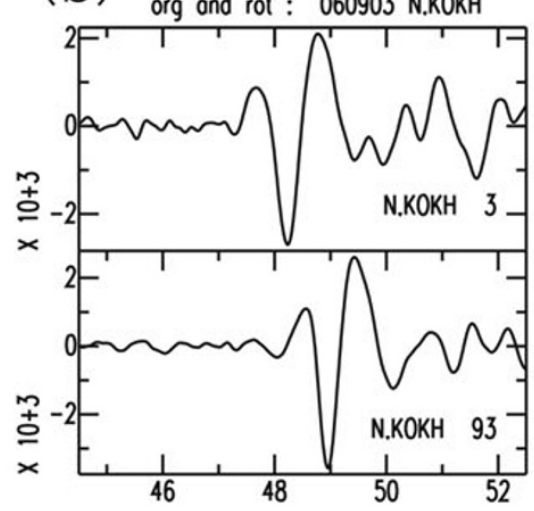

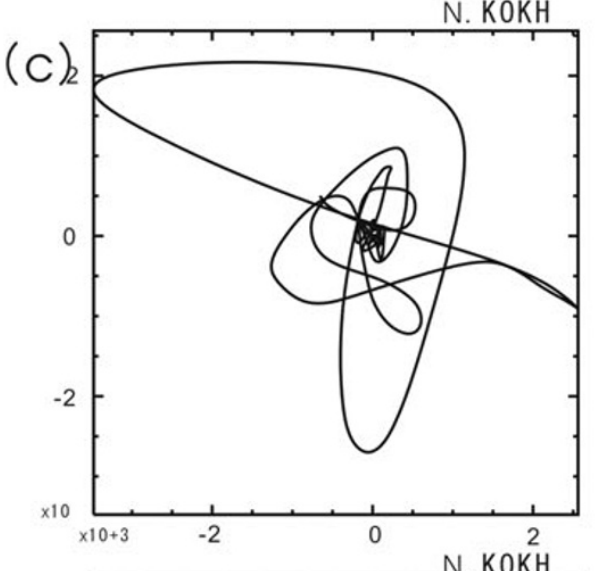

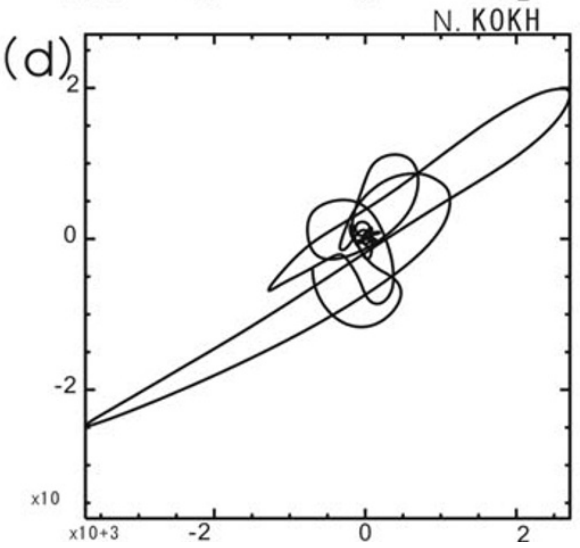

Fig. 2. Example of waveforms at two seismic stations (A and B). The original waveforms of the N-S and E-W components (a) and rotated waveforms with maximum cross-correlation (b), original particle motions (c) and anisotropy compensated particle motions (d). 


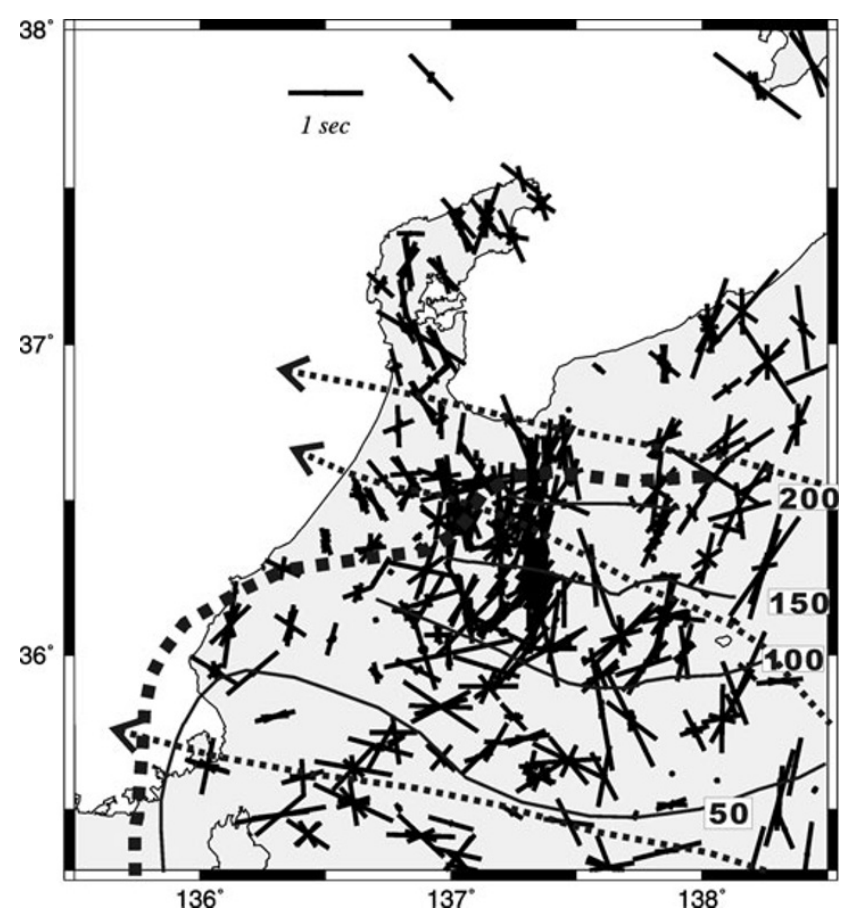

Fig. 3. Whole map of the polarization data of the research area. The polarization azimuths of maximum velocity and time delay between maximum and minimum velocity phases are shown by the direction and length of the bar, respectively. They are plotted at the location of the seismic station. The iso-depth lines of the subducting Philippine Sea plate obtained by Nakajima and Hasegawa (2007a) are shown by lines. The numbers indicate the depths of the iso-depth line. The north end of the subducting Philippine Sea plate as estimated by seismic tomography is shown by the thick broken line. The direction of the maximum horizontal compression estimated by Ando (1979) is shown by arrows with broken lines.

tion of the maximum horizontal compression direction at the most of the seismic stations (Mizuno et al., 2005). The time-lag data observed by Mizuno et al. (2005) was also very small $(0.02 \mathrm{sec}-0.07 \mathrm{sec})$. The maximum horizontal compression direction is different from that of the observed polarization direction in this study. The time-lag values observed here are also much larger than that of the shear-wave splitting cause by the crustal anisotropy obtained by Mizuno et al. (2005).

Time-lag values which are less than $0.2 \mathrm{sec}$ might be caused by the crust. The time-lag values, which are larger than $0.2 \mathrm{sec}$, are considered to be caused by the mantle. The averaged time-lag values are calculated (Table 2). The averaged time-lag values at Region A, Region B, Region C, and Region D are $0.51 \mathrm{sec}, 0.64 \mathrm{sec}, 0.60 \mathrm{sec}$, and $0.59 \mathrm{sec}$, respectively. In the Region $\mathrm{B}$, a large lateral variation of the time-lag values are found. The averaged time-lag value at the western part of the Region $\mathrm{B}$, that the longitude of the seismic station is smaller than $137.2^{\circ} \mathrm{E}$, was obtained to be $0.59 \mathrm{sec}$. On the other hand, the time-lag value of $0.69 \mathrm{sec}$ was obtained at the eastern side, that the longitude is larger than $137.2^{\circ} \mathrm{E}$, of the Region B. The velocity difference between the fast arrival phase and slow arrival phase was estimated. The estimated value of the velocity difference depends on the length of the ray path, because the observed time-lag data is the accumulated values of anisotropy at the whole ray path. There is a trade off between the ve- locity values and size of the anisotropic zone. The size of the anisotropic regions has to be obtained. Hiramatsu et al. (1998) tried to estimate the size of the anisotropic region in this area using ray paths with different azimuth. The anisotropic region in this area was estimated to be the horizontal size of $1.0 \mathrm{deg} . \times 0.5 \mathrm{deg}$. in depths of $100-175 \mathrm{~km}$. The velocity difference between the fast and slow phases in this study is estimated to be $3-5 \%$ based on the anisotropic region obtained by Hiramatsu et al. (1998). The velocity difference values are consistent with the value of 5\% estimated by Hiramatsu et al. (1998).

Next, we consider the cause of the anisotropy. We consider the olivine alignment model at first. Recently, many tomography studies indicated heterogeneous crustal and upper mantle structure using spatially high dense seismic networks. The configuration of the subducting Philippine Sea plate has been obtained by Nakajima and Hasegawa (2007a) (Figs. 3 and 5). The configuration of the subducting Philippine Sea plate is compared with the results of the shearwave splitting. Nakajima and Hasegawa (2007a) figured out that the subducting Philippine Sea slab was not smooth but distorted (Figs. 3 and 5). In Fig. 3, the iso-depth lines of the subducting Philippine Sea plate are shown on the map of the shear-wave splitting data. In the central and eastern parts of the area (eastern part of Region B and Region C), large shear-wave splitting values trending to NNE-SSW and NESW are obtained, respectively. In the area, the Philippine Sea plate is descending smoothly. However, at the western part of the research area where the small shear-wave splitting area lies (the western part of the Region B), suggests the configuration of the subducting Philippine Sea plate was deformed and disappeared. In the mantle wedge of this area, a low velocity zone which was sub-parallel to the down-dip direction of the subducting Philippine Sea slab was detected (Nakajima and Hasegawa, 2007a) (Fig. 5(c)). The geometry in this area is similar to back-arc side mantle wedge of NE Japan if we can neglect the subducting Pacific slab below the subducting Philippine Sea slab.

In NE Japan, a clear pattern on the polarization direction of shear-wave splitting was found (Nakajima et al., 2006). Trench-parallel and trench-normal polarization directions were found at the fore-arc side and back-arc side of the volcanic front, respectively. An inclined low-velocity zone, which was located sub-parallel to the down-dip direction of the slab, was imaged in the back-arc mantle wedge of northeast Japan and southwestern Kurile. It was interpreted as mantle return flow working as the main source of arc magmas. Two plausible candidates, fluid-fill cracks aligned under differential stress and lattice-preferred orientation of olivine, were considered as the anisotropy associated with the return flow. Numerical simulations have shown that crack faces would be aligned normal to the plate motion (e.g., Fischer et al., 2000), which results in trench-parallel fast-direction, and hence fluid-filled cracks would be ruled out as the sole explanation for the anisotropy in the back-arc mantle wedge. The observed anisotropy, which was parallel to the subduction direction, was interpreted by the latticepreferred orientation of olivine caused by the return flow.

In this research area, the polarization direction, which is parallel to the subduction direction of the Philippine Sea 


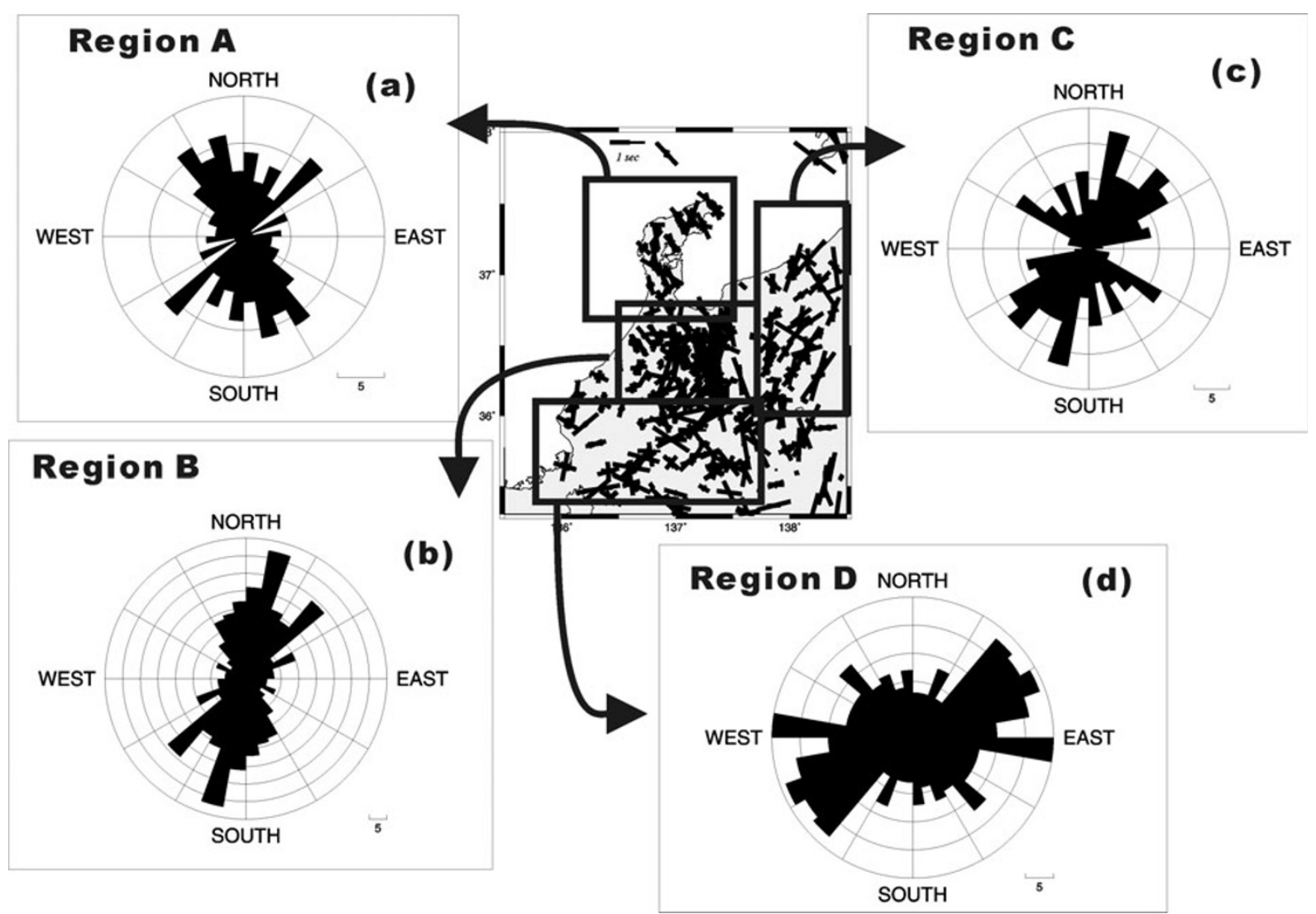

Fig. 4. Polarization data of $S$ waves from deep earthquakes. The polarization azimuths of the maximum velocity and the time delay between maximum and minimum velocity phases are shown by the direction and length of the bar, respectively. They are plotted at the location of the seismic station that received the signal. The rose diagrams showing the distribution of fast directions measured with the cross-correlation method. The observed data are divided into 4 regions: Region A which is located in the northern part of the research area (a), Region B which is located in the central part of the research area (b), Region C which is located in the eastern part of the research area (c), and Region D which is located in the southern part of the research area (d).

Table 2. Average (Ave.) and standard deviation (S. D.) of polarization direction and time-lag.

\begin{tabular}{ccccc}
\hline Region & Ave. azimuth (deg.) & S. D. azimuth (deg.) & Ave. time (sec.) & S. D. time (sec.) \\
\hline Region A & 165.8 & 32.5 & 0.51 & 0.18 \\
Region B & 9.7 & 35.0 & 0.64 & 0.25 \\
Region C & 16.7 & 38.0 & 0.60 & 0.33 \\
Region D & 86.9 & 48.5 & 0.59 & 0.33 \\
\hline
\end{tabular}

plate, and the existence of the low velocity zone at the mantle wedge are very similar to those of NE Japan. The observed polarization directions in Regions B and C could be interpreted by the preferred orientation of olivine crystals caused by the return flow in the mantle wedge (Fig. 5).

Second, we consider the melt filled cracks model. The cause of the large time-lag in our research area has been researched by previous studies (e.g., Ando, 1986; Hiramatsu et al., 1998). The anisotropic zone was interpreted to be caused by melt filled cracks as the rising magma in the mantle wedge (Ando, 1986; Hiramatsu et al., 1998) because a low velocity and low $Q$ area was detected below the seismic stations indicating large time-lag of shear-wave splitting (Hirahara et al., 1989; Nakamura et al., 1994). The olivine alignment model was ruled out because of the following argument (Hiramatsu et al., 1998). If the anisotropy is related to the alignment of the olivine crystal caused by the mantle flow, similar amplitude of anisotropy should be observed over the entire area because the scale of the mantle flow is considered to be large. The observation indicated that there are large differences in time-lag vales over the entire area. The olivine crystal has three axes with different $P$-wave velocity. In the case that the $b$-axis and $c$-axis directions are perturbed, the large lateral variation of the shear-wave splitting will be observed. However, the fast axis is aligned with the flow direction. The fast direction of the shear-wave splitting should be stable over the entire area.

According to the results of Nakajima and Hasegawa (2007a), a cross section of seismic tomography, which traverses the eastern part of Region B with NNE-SSW direction, indicated an extremely low velocity mantle wedge. The seismic stations located above the region indicate large shear-wave splitting values (eastern part of Region B and 

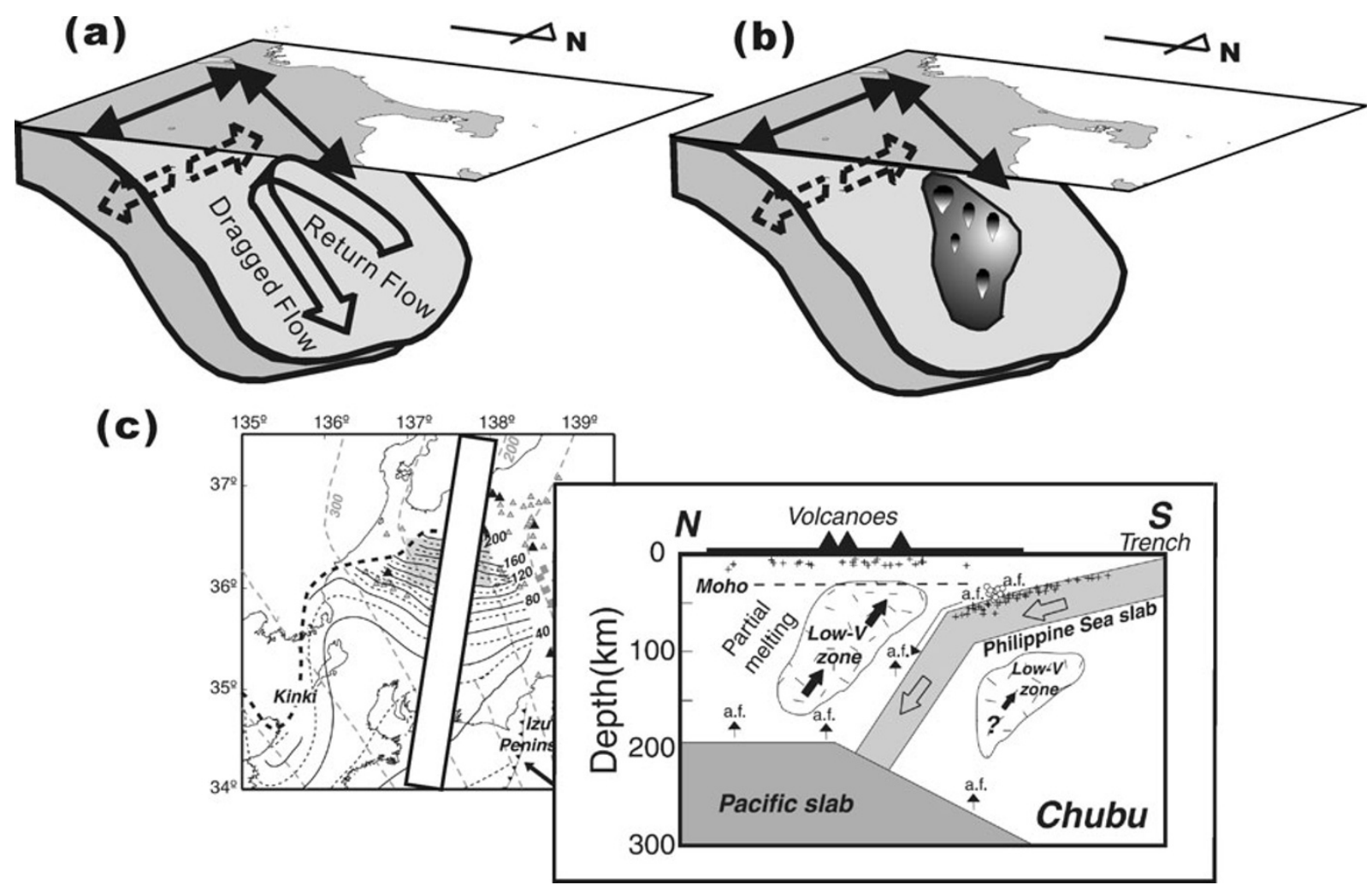

Fig. 5. Schematic figures of the olivine alignment model and melt filled cracks model are shown in (a) and (b), respectively. The configuration of the subducting Philippine Sea plate and schematic velocity structure in N-S direction obtained by Nakajima and Hasegawa (2007a) are shown in (c). The schematic vertical cross section (right) along the white square on the map (left) is shown. The schematic model was estimated from seismic tomography results (Nakajima and Hasegawa, 2007a). The "a.f." denotes aqueous fluids. In the olivine alignment model (a), the expected polarization direction was shown by solid arrow. The anisotropic region was caused by the flow which was shown by open arrows. In the melt filled cracks model (b), the anisotropic region was caused by the melt filled cracks which was supported by the low velocity zone obtained by seismic tomography (c). The anisotropic region with the polarization direction of broken arrows should be located beneath or inside the Philippine Sea slab.

Region C). A slightly smaller low velocity region was obtained in the mantle wedge at the western parts of Region B and of Region D. Small amplitude splitting is observed at the seismic stations above the zone. The large time-lag area lies above the extremely low velocity mantle wedge. Beneath the small-amplitude shear-wave splitting area was slightly lower velocity at the mantle wedge (Nakajima and Hasegawa, 2007a). The large lateral variation of the delay time is consistent with the lateral variation of heterogeneous structure. Numerical simulations have shown that crack faces would be aligned normal to the plate motion (Fischer et al., 2000). The trench-parallel polarization direction is expected from the simulation. However, the shear-wave reflects the elastic constant of the total volume which is related to the wave length. More detail study is necessary to declare the relation between the low-velocity area and shear-wave splitting. If the cause of the low-velocity area is related to the melt filled cracks, the melt filled cracks model could not be ruled out as the cause of the anisotropic zone.

The polarization directions at the Regions B and C can be explained by the olivine alignment model. The melt filled cracks model is also consistent with the observed results. The north end of the subducting Philippine Sea plate was obtained by the tomographic images (Figs. 3 and 5) (Nakajima and Hasegawa, 2007a). Region A is located to the north of the north end of the subducting Philippine Sea slab. The flow pattern in this area is expected to be complex. The
Philippine Sea plate and Pacific plate are descending into the north and west directions beneath the continental plate, respectively. The polarization direction of NW-SE in Region A might be related to the complex flow pattern caused by both of the subducting two plates.

At the Region $\mathrm{D}$, the polarization direction of $\mathrm{E}-\mathrm{W}$ is clearly different from that of the other regions. Hiramatsu et al. (1998) attributed the shear wave splitting in this region to another anisotropic zone, corresponding to a low velocity zone (Hirahara et al., 1989), beneath the subducting Philippine Sea slab in the mantle wedge. Recent experiments have yielded new insights into the diversity of olivine fabric (Jung and Karato, 2001; Katayama et al., 2004). Several fabric types are produced based on different conditions of stress and water content. The A-type fabric, assumed in the previous interpretation of seismic anisotropy, is dominant under low stress and low-water content. At higher water content other types of olivine fabric (B-, C-, and Etypes) are formed. The B-type fabric is formed under high stress and at higher water content conditions. B-type produces flow-normal fast directions. The C-and E-types are dominant under lower stress than suitable for the B-type and produce flow-parallel fast directions.

Numerical simulations for NE Japan predict hightemperature and low-stress conditions associated with the return flow, which are suitable for A-, C-, and E-types depending on water content (Kneller et al., 2005). The 
trench-normal fast directions were interpreted as the cause of olivine with fabrics of A-, C-, and E-types. In the model, on the other hand, B-type fabric was expected in the forearc mantle-wedge (Kneller et al., 2005; Long and van der Hilst, 2006). The fast direction of the Region $D$ is almost normal to the subduction direction of the Philippine Sea slab. The polarization direction, which is normal to the subduction direction, can be explained by the B-type fabric olivine. However, Kneller et al. (2005) pointed out that the forearc mantle-wedge with B-type fabric above the slab is a thin layer. It will not produce significant shear-wave splitting.

The depth of the subducting slab at Region D is about $40 \mathrm{~km}-70 \mathrm{~km}$. The crustal structure in this area was obtained by Iidaka et al. (2003). The thickness of the crust was estimated to be around $30 \mathrm{~km}$. The thickness of the mantle wedge in the Region D is estimated to be $10 \mathrm{~km}-$ $40 \mathrm{~km}$, which is too thin to produce large significant shearwave splitting, that the averaged time lag values in Region $\mathrm{D}$ is $0.59 \mathrm{sec}$. We do not have clear evidence to mention the location of the anisotropic area in this study. A low velocity zone below the Philippine Sea plate (Nakajima and Hasegawa, 2007a) seems to correspond to an anisotropic zone that causes the E-W polarization direction of Hiramatsu et al. (1998). We, thus, suggest that the anisotropic area might be located beneath the subducting slab as shown by Hiramatsu et al. (1998).

Finally, we discuss a cause of the NKTZ from the view of the shear wave splitting. No clear regional variation pattern was found along the NKTZ. Yamasaki and Seno (2005) suggested that heterogeneous structure at the uppermost mantle caused the NKTZ. However, our observed data does not support the heterogeneous structure along the NKTZ. No clear alignment of the polarization directions regarding to the NKTZ was found. Large lateral variation of polarization directions was found inside the NKTZ. The segmentation along the NKTZ was proposed from the seismic tomography results (Nakajima and Hasegawa, 2007b). The NKTZ was divided into three regions on the basis of the velocity structure. The cause of the NKTZ might not be uniform. If the NKTZ is a collision region (Shimazaki and Zhao, 2000; Heki and Miyazaki, 2001; Miyazaki and Heki, 2001), the NW-SE polarization direction of shear-wave splitting is expected. Because, the mantle flow direction is expected to be NW-SE. However, the lateral variation of the polarization direction does not support the collision model as the cause of NKTZ.

\section{Conclusions}

A high strain rate zone, which was called as the NKTZ, was detected at the central part of Japan (e.g., Sagiya et al., 2000). The elastic anisotropy of the earth is closely related to mantle dynamics. The research area has been studied by many scientists (e.g., Ando et al., 1986; Ando, 1986; Hiramatsu et al., 1998). But, a lack of seismic stations prevented to understanding the cause of the NKTZ. We conducted temporary seismic observations with 73 seismic stations at the NKTZ area (The Japanese University Group of the Joint Seismic Observations at NKTZ, 2005). The shear-wave splitting of the area was researched by the use of this dense seismic network.
A large lateral variation of polarization direction was found. The research area was divided into four regions based on the observed polarization directions. One is the northern part of the research area (Region A). In this area, the polarization direction was NW-SE. In the central part of the research area (Region B), the polarization directions were NNE-SSW. The eastern part of this research area indicated NE-SW directions (Region C). E-W polarization data was obtained at the seismic stations located in the southern part of the research area (Region D). The obtained velocity difference of 3-5\% between the fast and slow phases in this study was consistent with the results of previous studies. The value of the velocity difference is conformed by the use of spatially high dense array.

The polarization directions in the Regions B and C could be explained by the preferred orientation of olivine caused by the return flow induced by the subducting Philippine Sea plate. Alternatively, the melt filled cracks model could be plausible as the cause of the anisotropic zone. The Region A is located north of the north end of the subducting Philippine Sea slab. The NW-SE polarization direction in Region A might be related to the flows caused by both of the two subducting slabs; i.e., Philippine Sea slab and Pacific slab. The polarization direction at the Region D could not be explained by the return flow. But the anisotropic area might be located beneath the subducting Philippine Sea slab or inside the slab. From the large lateral variation of the shear-wave splitting data, we conclude that the cause of the NKTZ is not uniform. The shear-wave splitting data does not support the collision model as the cause of NKTZ.

Acknowledgments. We thank the National Research Institute for Earth Science and Disaster Prevention, Japan Meteorological Agency (JMA) for allowing us to use the waveform data collected at each online station. We thank Professor Savage who kindly checked this article. We also thank Professor Savage and anonymous reviewer for their comments. We use the unified hypocenter data by JMA. Most of the figures were created using GMT (Wessel and Smith, 1995). This was partly supported by a grant offered under the Earthquake Prediction Research program of the Ministry of Education, Culture, Sports, Science and Technology of Japan.

\section{References}

Ando, M., The stress field of the Japanese Island in the last 0.5 million years, Earth Mon. Symp., 7, 541-546, 1979 (in Japanese).

Ando, M., Mantle diapers observed in the seismic window, Bull. Volcanol. Soc. Jpn., 31, 45-53, 1986 (in Japanese with English abstract).

Ando, M., Y. Ishikawa, and F. Yamazaki, Shear-wave polarization anisotropy in the upper mantle beneath Honshu, Japan, J. Geophys. Res., 88, 5850-5864, 1983.

Audoine, E. L., M. K. Savage, and K. R. Gledhill, Anisotropic structure under a back-arc spreading region, the Taupo Volcanic Zone, New Zealand, J. Geophys. Res., 109, B11305, doi:10.1029/2003JB002932, 2004.

Bibee, L. D. and G. G. Shor, Jr., Compressional wave anisotropy in the crust and upper mantle, Geophys. Res. Lett., 3, 639-642, 1976.

Birch, F., The velocity of compressional waves in rocks to 10 kilobars, 1 , J. Geophys. Res., 65, 1083-1102, 1960.

Birch, F., The velocity of compressional waves in rocks to 10 kilobars, 2, J. Geophys. Res., 66, 2199-2224, 1961.

Crampin, S., Seismic-wave propagation through a cracked solid: Polarization as a possible dilatancy diagnostic, Geophys. J. R. Astron. Soc., 53, 467-496, 1978.

Crampin, S., A review of wave motion in anisotropic and cracked elasticmedium, Wave Motion, 3, 343-391, 1981.

Crampin, S., R. Evans, B. Ucer, M. Doyle, J. P. Davis, G. V. Yegorkina, and 
A. Miller, Observations of dilatancy-induced polarization anomalies and earthquake prediction, Nature, 286, 847-877, 1980.

Fischer, K. M. and X. Yang, Anisotropy in Kuril-Kamchatka subduction zone structure, Geophys. Res. Lett., 21, 5-8, 1994.

Fischer, K. M., E. M. Parmentier, A. R. Stine, and E. R. Wolf, Modeling anisotropy and plate-driven flow in the Tonga subduction back arc, $J$. Geophys. Res., 105, 16,181-16,191, 2000.

Francis, T. J. G., Generation of seismic anisotropy in the upper mantle along the mid-oceanic ridges, Nature, 221, 162-165, 1969.

Fuchs, K., Seismic anisotropy of the subcrustal lithosphere as evidence for dynamical processes in the upper mantle, Geophys. J. R. Astron. Soc., 49, 167-179, 1977

Fukao, Y., Evidence from core-reflected shear waves anisotropy in the Earth's mantle, Nature, 309, 695-698, 1984.

Gupta, I. N., Premonitory variations in $S$-wave velocity anisotropy before earthquakes in Nevada, Science, 182, 1129-1132, 1973.

Heki, K. and S. Miyazaki, Plate convergence and long-term crustal deformation, Geophys. Res. Lett., 28, 2313-2316, 2001.

Hess, H. H., Seismic anisotropy of the uppermost mantle under oceans, Nature, 203, 629-631, 1964.

Hirahara, K., A. Ikami, M. Ishida, and T. Mikumo, Three-dimensional $P$ wave velocity structure beneath central Japan: low-velocity bodies in the wedge portion of the upper mantle above high-velocity subducting plates, Tectonophys., 163, 63-73, 1989.

Hiramatsu, Y., M. Ando, T. Tsukuda, and T. Ooida, Three-dimensional image of the anisotropic bodies beneath central Honshu, Japan, Geophys. J. Int., 135, 801-816, 1998.

Hsui, A. T. and M. N. Toksoz, The evolution of thermal structures beneath a subduction zone, Tectonophys., 60, 43-60, 1979.

Hyodo, M. and K. Hirahara, A viscoelastic model of interseismic strain concentration in Niigata-Kobe Tectonic Zone of central Japan, Earth Planets Space, 55, 667-675, 2003.

Iidaka, T. and K. Obara, Shear-wave polarization anisotropy in the upper mantle from a deep earthquake, Phys. Earth Planet. Inter., 82, 19-25, 1994.

Iidaka, T. and K. Obara, Shear-wave polarization anisotropy in the mantle wedge above the subducting Pacific plate, Tectonophys., 249, 53-68, 1995 .

Iidaka, T., T. Iwasaki, T. Takeda, T. Moriya, I. Kumakawa, E. Kurashimo, T. Kawamura, F. Yamazaki, K. Koike, and G. Aoki, Configuration of subducting Philippine Sea plate and crustal structure in the central Japan region, Geophys. Res. Lett., 30, 23-1-23-4, 2003.

Iio, Y., T. Sagiya, Y. Kobayashi, and I. Shiozaki, Water-weakened lower crust and its role in the concentrated deformation in the Japanese Islands, Earth Planet. Sci. Lett., 203, 245-253, 2002.

Jung, H. and S. Karato, Water-induced fabric transitions in olivine, Science, 293, 1460-1463, 2001.

Kaneshima, S., Origin of crustal anisotropy: Shear wave splitting studies in Japan, J. Geophys. Res., 95, 11121-11133, 1990.

Katayama, I., H. Jung, and S. Karato, New type of olivine fabric from deformation experiments at modest water content and low stress, Geology, 32, 1045-1048, 2004.

Kneller, E. A., P. E. van Karen, S. Karato, and J. Park, B-type olivine fabric in the mantle wedge: Insights from high-resolution Non-Newtonian subduction zone models, Earth Planet. Sci. Lett., 237, 781-797, 2005.

Long, M. D. and R. van der Hilst, Shear wave splitting from local events beneath the Ryukyu arc: Trench-parallel anisotropy in the mantle wedge, Phys. Earth Planet. Inter., 155, 300-312, 2006.

Mazzotti, S., X. Le Pichon, and P. Henry, Full interseismic locking of the Nankai and Japan-west Kurile subduction zones: An analysis of uniform elastic strain accumulation in Japan constrained by permanent GPS, $J$. Geophys. Res., 105, 13159-13177, 2000.

McKenzie, D., Finite deformation during fluid flow, Geophys. J. R. Astron. Soc., 58, 689-715, 1979.

Mendiguren, J. A., Study of mechanisms deep earthquakes in Argentina using non-linear particle motion of S waves, Bull. Seismol. Soc. Am., 59, 1449-1473, 1969.
Miyazaki, S. and K. Heki, Crustal velocity field of southwest Japan: Subduction and arc-arc collision, J. Geophys. Res., 106, 4305-4326, 2001.

Mizuno, T., H. Ito, Y. Kuwahara, K. Imanishi, and T. Takeda, Spatial variation of shear-wave splitting across an active fault and its implication for stress accumulation mechanism of inland earthquakes: The Atotsugawa fault case, Geopys. Res. Lett., 32, L20305, doi:10.1029/2005GL023875, 2005.

Nakajima, J. and A. Hasegawa, Shear-wave polarization anisotropy and subduction-induced flow in the mantle wedge of northeastern Japan, Earth Planet. Sci. Lett., 225, 365-377, 2004.

Nakajima, J. and A. Hasegawa, Subduction of the Philippine Sea plate beneath southwestern Japan: Slab geometry and its relationship to arc magmatism, J. Geophys. Res., 112, B08306, doi:10.1029/2006JB004770, 2007a.

Nakajima, J. and A. Hasegawa, Deep crustal structure along the NiigataKobe Tectonic Zone, Japan: Its origin and segmentation, Earth Planets Space, 59, e5-e8, 2007b.

Nakajima, J., J. Shimizu, S. Hori, and A. Hasegawa, Shear-wave splitting beneath the southwestern Kurile arc and northeastern Japan arc: A new insight into mantle return flow, Geophys. Res. Lett., 33, L05305, doi:10. 1029/2005GL025023, 2006.

Nakamura, R., K. Shimazaki, and T. Hashida, 3-D attenuation structure beneath the Japanese Islands by tomographic inversion of seismic intensity data and predicting JMA seismic intensity distribution in a broad area, Zisin, 47, 21-32, 1994 (in Japanese with English abstract).

Nicolas, A. and N. I. Christensen, Formationof anisotropy in upper mantle peridotites-A review, in Composition, Strustutre and Dynamics of the Lithosphere-Asthenosphere System, edited by K. Fucks and C. Froidevaux, Geodyn. Ser., AGU, 16, 111-123, 1987.

Nur, A. and G. Simmons, Stress induced anisotropy in rocks: An experimental study, J. Geophys. Res., 74, 6667-6674, 1969.

Nuttli, O., The effect of the earth's surface on the S wave particle motion, Bull. Seismol. Soc. Am., 51, 237-246, 1961.

Peselnick, L. and A. Nicolas, Seismic anisotropy in ophiolite peridotite: Application to oceanic upper mantle, J. Geophys. Res., 83, 1227-1235, 1978.

Peselnick, L., A. Nicolas, and P. R. Stevenson, Velocity anisotropy in a mantle peridotite from the Iverea zone, application to upper mantle anisotropy, J. Geophys. Res., 79, 1175-1182, 1974.

Sagiya, T., S. Miyazaki, and T. Tada, Continuous GPS Array and Presentday crustal deformation of Japan, Pure. Appl. Geophys., 157, 23032322, 2000.

Sekiguchi, S., Three-dimensional $Q$ structure beneath the Kanto-Tokai district, Tectonophys., 195, 83-104, 1991.

Shimazaki, K. and Y. Zhao, Dislocation model for strain accumulation in a plate collision zone, Earth Planet. Sci. Lett., 52, 1091-1094, 2000.

Silver, P. G. and W. W. Chan, Shear wave splitting and subcontinental mantle deformation, J. Geophys. Res., 96, 16429-16454, 1991.

Sugimura, A. and S. Uyeda, A possible anisotropy of the upper mantle accounting for deep earthquake faulting, Tectonophys., 5, 25-33, 1967.

Tatsumi, Y., M. Sakuyama, H. Fukuyama, and I. Kushiro, Generation of arc basalt magmas and thermal structure of the mantle wedge in subduction zones, J. Geophys. Res., 88, 5815-5825, 1983.

The Japanese University Group of the Joint Seismic Observations at NKTZ, The university joint seismic observations at the Niigata-Kobe Tectonic Zone, Bull. Earthq. Res. Inst., Univ. Tokyo, 80, 133-147, 2005.

Wessel, P. and W. H. F. Smith, New version of the Generic Mapping Tools Released, Eos Trans. AGU, 76, 329, 1995.

Yamasaki, T. and T. Seno, High strain rate zone in central Honshu resulting from the viscosity heterogeneities in the crust and mantle, Earth Planet. Sci. Lett., 232, 13-27, 2005.

T. Iidaka (e-mail: iidaka@eri.u-tokyo.ac.jp), Y. Hiramatsu, and The Japanese University Group of the Joint Seismic Observations at NKTZ 